\title{
Adverse childhood experiences and impact on quality of life in adulthood: development and validation of a short difficult childhood questionnaire in a large population-based health survey
}

\author{
John-Kåre Vederhus ${ }^{1,3}$ (D) Christine Timko² $\cdot$ Siri Håvås Haugland ${ }^{3}$ (D)
}

Accepted: 8 January 2021 / Published online: 3 February 2021

(c) The Author(s) 2021

\begin{abstract}
Purpose A short adverse childhood experiences (ACEs) measure is needed with non-intrusive items that include subjective evaluations of childhood. We validated a short Difficult Childhood Questionnaire (DCQ) that assesses ACEs using personal perceptions of events.

Methods The study relied on 2019 data from a representative survey $(N=28,047)$ in Norway. We examined the DCQ's factor structure, internal consistency, and discriminant validity in a multi-group confirmatory factor analysis. As a group variable, we used whether the respondent had the ACE of parental alcohol use disorder (adult children of alcoholics; ACOA). To assess the DCQ's convergent validity, we used latent regression analysis with adulthood quality of life (QoL) as the outcome and mental distress and loneliness as potential mediators.

Results The DCQ's latent mean was 0.86 (95\% CI0.82-0.90, $p<0.001$ ) higher in the ACOA versus the non-ACOA group. The effect size suggested a large magnitude of this difference. The DCQ score was negatively associated with QoL and positively associated with mental distress and loneliness. For the score's QoL effect [ -0.84 (95\% CI -0.87 to $-0.80, p<0.001)]$, -0.80 was indirect, and -0.04 was direct. Thus, most of the association of DCQ with QoL occurred via mediators.

Conclusions The results confirmed the DCQ's discriminant and convergent validity and highlight this tool as an empirically supported approach to assess ACEs. Because of its brevity and psychometric strengths, the DCQ is useful for research and likely suited to mental health treatment settings.
\end{abstract}

Keywords Adverse childhood experiences · Quality of life · Parental alcohol use $\cdot$ Mental health · Confirmatory factor analysis

John-Kåre Vederhus

john-kare.vederhus@sshf.no

Christine Timko

ctimko@stanford.edu

Siri Håvås Haugland

siri.h.haugland@uia.no

1 Addiction Unit, Sørlandet Hospital, P.b. 416, 4604 Kristiansand, Norway

2 Center for Innovation to Implementation, Veterans Affairs Health Care System and Stanford University School of Medicine, Palo Alto, CA, USA

3 Department of Psychosocial Health, University of Agder, Grimstad, Norway

\section{Plain English Summary}

A short measure of adverse childhood experiences with nonintrusive items is needed for assessing a person's subjective evaluation of childhood. This study validated a short Difficult Childhood Questionnaire (DCQ) with data from a large, Norwegian public health survey $(N=28,047)$ in 2019 . The DCQ discriminated well between a group with the adverse experience of having parents with an alcohol use disorder (adult children of alcoholics; ACOA) and a group without this experience. The ACOA group had DCQ scores that were 0.86 higher than the unexposed group, which was deemed a substantial difference. We also examined the relationship between the DCQ and adulthood quality of life (QoL), and the DCQ score was associated with a direct but rather weak negative influence on QoL, along with increased mental distress and loneliness. When including the mediated effects 
via mental distress and loneliness, the DCQ score led to an almost full point $(-0.84)$ worse QoL score, with -0.80 representing indirect effects. Thus, most of the QoL effect associated with the DCQ score could trace to these potential aftermaths of adverse experiences in childhood, rather than being directly represented by the DCQ score itself. Because it is brief and potentially amenable for people seeking mental health treatment, the DCQ would likely be well suited to clinical settings. Its psychometric strengths render it useful for research purposes.

\section{Background}

Childhood adversities are prevalent [1-3], and no matter how they are measured, the association between these experiences and poor adult physical and mental health has been repeatedly confirmed [3-5]. More than 25\% of cases of both anxiety and depression in Europe can be attributed to adverse childhood experiences (ACEs) [1], and a U.S. study found that patients with mood disorders were more likely to have a history of ACEs compared with the general population [6]. The relationship between ACEs and poor mental health is therefore recognized as an important focus area globally for prevention of non-communicable diseases [7]. Given these associations, as would be expected, ACEs are negatively associated with general and overarching concepts of health, such as quality of life (QoL) and well-being $[8,9]$.

One way that ACEs influence health is through social relationships $[10,11]$. A stable and trustful environment helps a child build positive views of self and others and develop positive expectations regarding close ties [12]. Insecurity about relationships with important others limits trust in the world, leading to pessimistic views regarding social interactions [12]. Social connection to others is a powerful predictor of health and well-being [13, 14]. Conversely, lack of social connection, such as social isolation and loneliness, enhances risk for negative health outcomes and mortality $[12,15,16]$.

Identifying adults with childhood experiences that could have affected their current health and well-being is relevant in clinical settings and from a public health perspective. Typical measures focus on parameters such as types of experience (e.g., family dysfunction, emotional/physical abuse, sexual abuse) and parameters for quantifying the experience (e.g., frequency of traumatic events, severity of the adverse experience). In many cases, this approach has led to instruments [17] with a length that may prevent inclusion of this topic in larger health surveys and records. Compared with the suggested 3-item scale in the present article, we note that the shortest reflective measure in a previous review of measurements in this field had 22 items [17].
The original and most common way to calculate ACE scores is to add up the number of "yes" responses to questions about specific maltreatment exposures before age 18 years and use the sum as a proxy for severity, sometimes called the ACE "dose" [18]. Previous findings indicate a "dose-response" relationship, and the cumulative impact on health problems is evident across the lifespan. For example, Chapman et al. found that the number of ACEs had a graded relationship to both lifetime and recent depressive disorders [19]. Having at least one ACE, such as a childhood experience of problematic alcohol use by a household member, also has been linked to the probability of having other adverse childhood experiences [20,21].

The path from childhood adversities to later health problems is not inevitable, and children can become resilient adults, for example through available social support as emerging adults [22, 23]. For this reason, one helpful approach may be to use a paradigm with enhanced weight on resilience and ways of coping with an adverse experience. With such a paradigm, reflective items, such as self-perceived severity, might be better choices for inclusion rather than using only the sum of formative (objective) indicators, i.e., whether certain adverse experiences happened. The list of possible ACEs with potential to be traumatic for children (e.g., peer rejection and bullying) is much longer than the original ACE questionnaire list, yet these experiences would not be counted with formative indicators, simply because they are not mentioned [24].

A known problem in clinical settings is that patients may be reluctant to reveal that they had traumatic childhood experiences because of feelings of shame or unpreparedness when queried (for example, when a trauma has been more or less encapsulated), with a consequent risk of disrupting the relationship with health professionals [25]. Even simply screening for ACEs can potentially feel intrusive, raise discomfort, and add to a sense of stigma for the patient [24]. Direct and blunt questions about sexual abuse, for example, may then be non-therapeutic (e.g., "Did an adult or person at least 5 years older ever actually have oral, anal, or vaginal intercourse with you?) [26]. It would be sensible to use more global and generally worded items to avoid awkwardness and risk of stigmatization.

\section{Objectives}

A brief ACE measure is needed that uses non-intrusive items that include subjective evaluations of the experiences. Accordingly, the aim of this study was to validate a short Difficult Childhood Questionnaire (DCQ) that assesses ACEs using non-stigmatizing items and personal perceptions of events. We examined the DCQ's factor structure, internal consistency, and discriminant validity in a multi-group 
confirmatory factor analysis (MGCFA). We hypothesized that a group that had experienced a typical ACE (exposure to parental alcohol problems) would score higher on the DCQ than those who had not had this experience. Finally, we examined the convergent validity of the DCQ and hypothesized that it would be positively associated with mental distress and loneliness and negatively associated with QoL.

\section{Methods}

\section{Participants and procedures}

During autumn 2019, a representative sample of inhabitants $(N=61,611)$ from 30 municipalities in Southern Norway aged 18 or older were invited to complete an online survey with questions related to health, well-being, childhood, living conditions, local environments, accidents, and injuries. Invitations were based on randomly selected participants drawn from the Norwegian Population Registry of inhabitants in Southern Norway, and contact information (e-mail or telephone number) was retrieved from the contact registry from the Agency for Public Management and eGovernment (Difi). An online consent was provided as the participants answered the survey. Of the 61,611 invited respondents, a total of 28,047 completed the questionnaire, for a response rate of $45.5 \%$. The study had a cross-sectional design with retrospective assessment of childhood experiences, as described below.

\section{Measures}

$D C Q$. The DCQ was developed for and used in a large Norwegian public health study (the HUNT study). In HUNT 3, the third wave of this study, a single item was used (Q3 in Table 1) that allowed respondents to give a general evaluation of their childhood. The results based on this query showed strong relationships between perceiving childhood as difficult and a range of health-related outcomes [27]. For the fourth wave of the study (HUNT 4), the HUNT team thus sought to place greater focus on the theme of childhood difficulties. The overall questionnaire is quite long so that any addition had to be brief, preferably no more than two extra questions. Based on what was identified as the most important concepts, a question about communication and conflict level in the family (Q1 in Table 1) was included, as was a question about childhood trauma (Q2 in Table 1). To avoid potential embarrassment, the latter question was formulated indirectly to assess whether respondents struggled with difficult memories about adverse experiences during childhood because of loss, violence, or abuse. The items were scored on a 5-point ordinal scale (from "not at all" to "very much"), and higher scores represented greater perceived difficulties in childhood. The overall HUNT 4 survey was pilot tested in the municipality of Selbu. Respondents $(N=31)$ provided written comments to the questions, and six of these respondents were interviewed in detail by phone. A special focus was whether the questions were comprehensible and whether the respondents considered them to be inappropriate or too sensitive in nature. The items in the DCQ seemed to work well, and the pilot respondents offered no negative opinions.

$S C L-5$. To measure mental distress, we used a short version of the Hopkins Symptom Checklist, the SCL-5 [28]. The SCL-5 performs almost as well as more extended versions (SCL-10 and SCL-25), and the reliability of the scale was excellent in the Norwegian validation study (Cronbach's alpha $=0.87$ ) [29]. Participants reported whether at any time in the previous week they had felt sad or depressed, hopeless about the future, tense or keyed up, constantly fearful and anxious, or worried. Response categories are "not bothered," "a little bothered," "bothered quite a lot," and "extremely bothered," scored 1-4. Higher scores indicate greater mental distress.

Table 1 The questions of the DCQ

\begin{tabular}{ll}
\hline Item & Questions: \\
\hline Q1 & Var det mye krangling, uro, konflikter eller vanskelig kommunikasjon i barndomshjemmet? \\
& Translation: Did you grow up in a home marked by arguments, tension, conflicts, or poor communication? \\
Q2 & Sliter du med vonde minner fra oppveksten pga. tap, svik, vanskjøtsel, vold, mishandling eller misbruk? \\
& Translation: Do you struggle with childhood memories of loss, violence, or being let down, abandoned, \\
& neglected, maltreated, or abused? \\
Q3 & Når du tenker på barndommen/oppveksten din, vil du beskrive den som? \\
& Translation: When you think about your childhood, how would you describe it? \\
\hline
\end{tabular}

Response categories

Q1 and Q2: to a very great extent/ to a great extent/ to a limited extent/ to a very limited extent/ not at all (responses were reverse coded, so that higher scores indicate greater problems)

Q3: very good/ good/ average/ difficult/ very difficult 
Loneliness scale: The Three-Item Loneliness Scale is a short version of the UCLA Loneliness Scale [30]. In a validation study, the reliability of the scale was acceptable (Cronbach's alpha $=0.72)$ and appeared to measure overall loneliness quite well. This scale contains questions about how often the respondent feels a lack of companionship, left out, and isolated from others. The scale was developed for use in telephone surveys and has a simplified set of response categories. In the present online survey, the 5-point response categories ranged from "never" to "very often," and higher scores indicate greater loneliness.

CAST-6. The questionnaire included the CAST-6 scale [31], used to assess whether or not participants perceived their parents' alcohol consumption as problematic. CAST-6 is a brief version of the 30-item Children of Alcoholics Screening Test (CAST) [32] and has demonstrated high internal consistency and test-retest reliability. In a previous validation study, the Cronbach's alpha ranged from 0.86 to 0.92 for students and patients being treated for substance use disorder [31]. The validity of the CAST- 6 has been confirmed in adult populations $[31,33]$ and among adolescents [34]. Items include questions about whether respondents have ever thought of one of their parents as having a drinking problem, encouraged one of their parents to quit drinking, argued with a drinking parent, heard parents fight when drinking, or felt like hiding or emptying a parent's bottle of alcohol, and whether they had wished their parent would stop drinking. Response categories for the six items are yes/ no. Responses are summed (scale 0-6), and for this study, a score of $\geq 3$ was defined as a parental alcohol problem. The original measure used the term "adult children of alcoholics" (ACOA). For simplicity, we also use this term, although we note that "alcoholics" is now outdated, and first-person language is preferred ("children of parents who had problematic alcohol use") [35].

QoL. We used three items representing subjective QoL, all of which have been suggested as part of a "minimum" list for measuring QoL in national public health surveys in Norway [36]. The items represent three dimensions of subjective QoL: cognitive (satisfaction with life), affective (positive feelings such as happiness), and eudaimonic (whether life is perceived as meaningful) [37, 38]. Conceptually, the first two items address classical subjective well-being (hedonic). The third item builds on the Aristotelian view that a "good life" comprises not only desire fulfillment but also whether a person lives up to their perceived potential or in accordance with their perceived purpose in life. The items are rated on $0-10$-point scales, with higher scores representing more satisfaction, happiness, and perceived meaningfulness in life. To our knowledge, these items have not been validated as an expression for QoL in a latent variable analysis before using a structural equation modeling (SEM) framework. Because we used this scale as an outcome measure in our mediation analysis and associations are bi-directional, our findings indirectly assessed the convergent validity for the QoL scale. In other words, the analysis indicated whether the associations of QoL with the DCQ scores and the mediators were in the expected direction. We also report the internal consistency of the scale.

\section{Statistical analyses}

Descriptive statistics are used to show sample characteristics. The constructs used in the following analyses were handled as latent variables in a SEM framework, so that the questions were modeled as reflective indicators of their respective constructs [39]. Mplus version 8.4 was used for the analyses. Because of the ordinal nature of the DCQ, we used the maximum likelihood estimation with robust standard errors (MLR) and report standardized factor loadings $($ beta $=\beta)[40]$. The default procedure in Mplus, full information maximum likelihood, handled missing values. The significance level was set at $p<0.05$. The root mean square error of approximation (RMSEA) and the comparative fit index (CFI) were used to assess goodness of fit, with a cutoff value for a good model fit of 0.05 or less for RMSEA and 0.95 or higher for CFI [41, 42].

We assessed the discriminant validity of the DCQ with an MGCFA, examining whether the DCQ discriminated between a group with expected higher negative childhood experiences (ACOA) versus a group without these experiences (non-ACOA). To legitimately be able to compare means between the two groups, we first examined whether the DCQ measured the construct similarly in the two groups to ensure that the construct was invariant (equivalent) across groups [43]. First, we established a configural (baseline) model. The reliability of the scale is reported with the composite reliability (CR) value [44], and a CR value of $>0.70$ is considered acceptable. For convenience, we also added McDonald's omega coefficient [45].

We then implemented a simultaneous MGCFA with increasing equality constraints on measurement parameters to examine if the scale had strong measurement invariance (scalar equivalence) across groups. Scalar equivalence implies that the scales have the same factor structure (configural equivalence) and equivalent factor loadings (metric equivalence) across groups, as well as invariant intercepts, with equivalent origin on the scales in the different groups [46]. If scalar invariance is not achieved, intercepts of the non-invariant items could be freed to assume partial scalar equivalence, which is still considered sufficient for comparing latent means if at least two items are metrically invariant per factor [47]. The testing implies that the more restricted models are compared with the less restricted models, and chi-square differences between the nested models illustrate whether differences in the chi-square value $\left(\Delta \chi^{2}\right)$ relative to 
the change in degrees of freedom $(\Delta \mathrm{df})$ are significant [40]. A non-significant $\Delta \chi^{2}$ value indicates that constraining does not worsen the fit of the model and that the null hypothesis of measurement invariance can be retained [48]. However, Cheung and Rensvold found in a simulation study that the chi-square test might be too conservative, especially in large samples, running the risk of being too likely to deem a measure as non-invariant $[49,50]$. They recommended using the change in CFI $(\triangle \mathrm{CFI})$, which sample size does not affect. A value of $\Delta C F I$ less than or equal to -0.01 indicates that the null hypothesis of invariance should not be rejected [49]. Latent mean differences are reported as unstandardized $\beta$ values with $95 \%$ confidence intervals (CIs).

We assessed the convergent validity of the DCQ by examining whether the score was related in the expected direction with constructs from the literature that are known to correlate with adverse childhood experiences (mental distress, loneliness, and QoL). Results of this latent regression analysis are reported with unstandardized $\beta$ and $95 \%$ CI values to facilitate interpretation of the associations between constructs. The $R$ square $\left(R^{2}\right)$ value was used to assess the percentage of the variation in the latent constructs explained by the model.

\section{Results}

\section{Participant characteristics}

Most of the participants (76\%) were between 25 and 66 years old, slightly more than one-half (53\%) were female, about one-half had a higher educational level (at least a bachelor's degree), and 8 in 10 lived with a spouse or partner (Table 2).

Table 2 Participant characteristics $(N=28,047)$

\begin{tabular}{ll}
\hline & $\mathrm{N}(\%)$ \\
\hline Age group & \\
18-24 years & $3169(11)$ \\
$25-44$ years & $9180(33)$ \\
45-66 years & $12,026(43)$ \\
67-79 years & $3372(12)$ \\
80+ years & $300(1)$ \\
Female sex & $14,925(53)$ \\
Educational level ( $n=27,923)$ & \\
$\quad$ Primary and secondary school (up to 10 years of & $3333(12)$ \\
$\quad$ education) & \\
$\quad$ High school (up to 13 years of education) & $11,088(40)$ \\
$\quad$ University college or university (bachelor's degree or & $13,502(48)$ \\
$\quad$ higher) & \\
Living with a spouse or partner ( $n=27,977)$ & $21,893(78)$ \\
Child of parent(s) with a problematic alcohol use & $4346(16)$ \\
$\quad(n=27,895)$ & \\
\hline
\end{tabular}

According to the CAST-6, about one in six was defined as a child of a parent(s) who had a problematic alcohol use (ACOA).

\section{Internal consistency and discriminant validity of the DCQ}

The covariance coverage of the indicators used in the following analyses were good, above $98.8 \%$ in all cases. The first step was specification of the baseline model of the DCQ for each group (Fig. 1). This one-factor solution had "perfect" goodness-of-fit values (RMSEA $=0.00$ and CFI $=1.00$ ). Although a model with three indicators is "just-identified" and goodness-of-fit evaluation does not apply, the model can still be evaluated in terms of interpretability and strength of its parameter estimates (e.g., magnitude of factor loadings) [51]. The model had factor loadings from 0.69 to 0.89 in both groups, and no error correlations emerged. The baseline model for the ACOA group is shown in Fig. 1. The reliability of the scale was excellent $(\mathrm{CR}$ and omega coefficient $=0.86$ ).

The MGCFAs specifying the $\chi^{2}$ and CFI values for the configural, metric, and scalar models are shown in Table 3. In case of the metric and scalar models, these values have positive degrees of freedom, as more restrictions were set on the model. Thus, they are over-identified models, and comparison between them is legitimate [51]. The $\Delta \chi 2 \mathrm{~s}$ between the nested models were significant as expected because of the large number of participants; thus, further investigation was based on $\Delta$ CFIs. The scalar model had a 0.03 lower CFI value compared with the metric model, and its RMSEA was too high, indicating a problem. The modification indices indicated that the intercept of Q1 (Table 1)

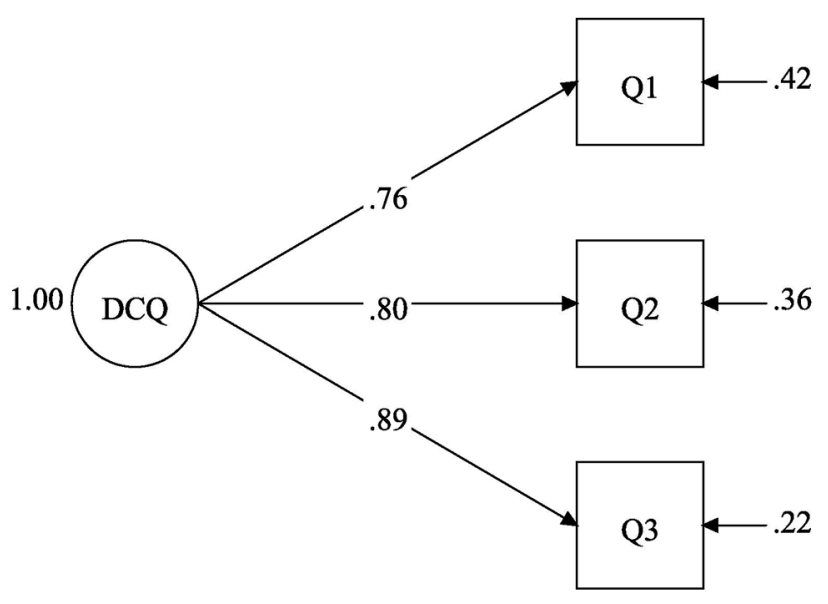

Fig. 1 Baseline model for the difficult childhood questionnaire (DCQ). The model was similar across groups, and the figure shows the standardized factor loadings and residual (error) variances for the adult children of alcoholics (ACOA) group. Q1-Q3 refers to the indicators (questions) shown in Table 1 
Table 3 Multigroup confirmatory factor analysis results of the measurement invariance tests across the two groups: ACOA $(n=4346)$ and non-ACOA $(n=23,549)$

\begin{tabular}{lllll}
\hline & $\chi^{2}$ & $d f$ & RMSEA & CFI \\
\hline Configural model & 0.00 & 0 & 0.00 & 1.00 \\
Metric model & 51 & 2 & 0.04 & 1.00 \\
Scalar model & 618 & 4 & 0.11 & 0.97 \\
Partial scalar model & 100 & 3 & 0.05 & 1.00 \\
\hline
\end{tabular}

Note: 152 had missing data on all variables used in the analysis ACOA Adult children of alcoholics; CFI Comparative fit index; $R M S E A$ Root mean square error of approximation

was non-invariant and that the $\Delta \chi 2$ would improve considerably if this intercept was freed. The final partial scalar model had excellent fit and was deemed as invariant because the $\Delta \mathrm{CFI}$ was $\leq-0.01$ (Table 3 ), so latent means could be compared. The latent mean of the DCQ scale was $0.86(95 \%$ CI $0.82-0.90, p<0.001)$ higher in the ACOA group versus the non-ACOA group. To examine the magnitude of this value, we calculated an effect size $d$ for the latent mean differences following the procedure proposed by Hancock [52]. The effect size $d$ for the ACOA versus the non-ACOA group was 1.15 (see calculation in additional file). According to interpretative guidelines, 0.2, 0.5 , and 0.8 are cut-off values for small, medium, and large effect sizes of latent means, respectively, which indicates a large effect size of differences between groups [52].

\section{Convergent validity}

Continuing to the convergent validity analyses, we tested the relationship between the DCQ and adulthood QoL in a simultaneous mediation analysis that included mental distress (SCL-5) and loneliness as mediating constructs. The DCQ scores had a direct negative association with QoL $(\beta=-0.04,95 \% \mathrm{CI}-0.07$ to $-0.02, p=0.001 ;$ Fig. 2$)$. The DCQ scores were associated in the expected direction with both mental distress $(\beta=0.31,95 \%$ CI $0.30-0.33, p<0.001)$ and loneliness $(\beta=0.38,95 \%$ CI $0.36-0.39, p<0.001)$, i.e., the level of mental distress and loneliness increased when the DCQ score increased. In turn, mental distress and loneliness had a substantial negative influence on $\operatorname{QoL}(\beta=-1.56$ and $\beta=-0.81$, respectively; Fig. 2). The specific indirect effect of the DCQ score in association with QoL (shown only in the Mplus output, not in the figure) via mental distress was $\beta-0.49$ (95\% CI -0.51 to $-0.46, p<0.001$ ). The specific indirect effect of this score in association with QoL via loneliness was $\beta-0.31$ (95\% CI -0.33 to -0.29 , $p<0.001)$. Thus, the DCQ accounted for $31 \%$ of the influence of the mental distress construct $(-0.49 /-1.56)$ on QoL and $38 \%$ of influence of the loneliness construct on QoL $(-0.31 /-0.81)$. The total influence of the DCQ score in association with QoL was -0.84 (95\% CI -0.87 to -0.80 , $p<0.001$ ), and of this value, -0.80 was indirect and -0.04 direct. The model as a whole had excellent goodness-offit indices (RMSEA $=0.05$ and $\mathrm{CFI}=0.98$ ) and explained $18 \%$ of the variance in mental distress, $19 \%$ of the variance

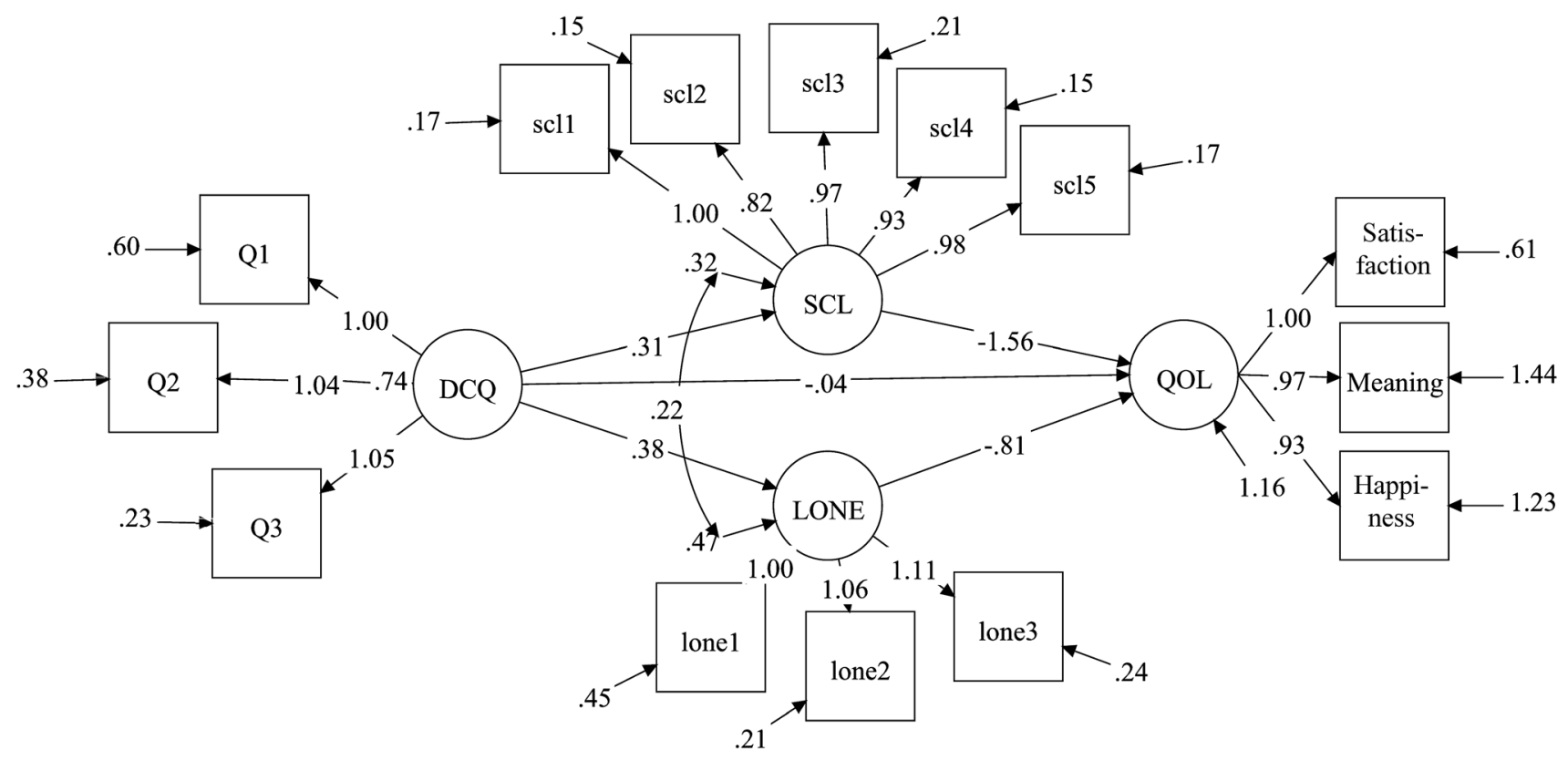

Fig. 2 Latent regression analysis showing the association of Difficult Childhood Questionnaire (DCQ) scores with adulthood quality of life (QoL) and the effect of two mediators, mental distress (SCL) and loneliness (Lone). The figure shows the measurement and the structural model with unstandardized factor loadings 
in loneliness, and $65 \%$ of the variance in QoL $\left(R^{2}\right)$. The reliability of the QoL scale was excellent (CR and omega coefficient $=0.90$ ).

\section{Discussion}

This analysis confirmed the discriminant validity of the DCQ, with a group who had experienced a prevalent ACE reporting substantially higher scores on the DCQ than their counterparts without this experience (parental problematic alcohol use). The convergent validity of the DCQ was also confirmed, showing associations in the expected direction with tools that measure potential sequela of ACEs: loneliness, adverse mental health outcomes, and decreased QoL. The main association of the DCQ score with QoL could be attributable to the mediating constructs of mental distress and loneliness.

The findings support the hypothesis that the DCQ could be a valid and useful measure in large public health surveys. Of note, the wording of the DCQ assesses ACEs indirectly, with phrasing in terms of difficult memories. The DCQ also lumps several possible ACEs together in the same question, which may make respondents feel less exposed than the direct and blunt approach used in the original ACE measure. Thus, the DCQ approach will likely be perceived as less intrusive and stigmatizing and more in line with the relationship requirements of a modern clinical practice paradigm. In clinical settings, the DCQ could serve as a sensitive first step to map whether childhood adversities may be an issue, while still attending to the development of a trusting provider-patient relationship [25].

The original ACE questionnaire is still in use in several large-scale public health surveys, such as the Behavioral Risk Factor Surveillance System, conducted by the U.S. Centers for Disease Control and Prevention to collect data on health practices and behavioral risk factors among U.S. adults [53]. The original ACE questionnaire has even been launched online on various websites such as "Get your ACE score" or "Take the ACE quiz" [54, 55]. Although such sites typically feature a disclaimer about what the questionnaire does and does not mean, people who take the test are at risk of inferring an inevitable link between a higher score and later negative health consequences. The ACE score does not consider positive experiences in early life that could help build resilience and protect a child from the effects of trauma, and this omission is easy to overlook [54].

An important finding in the current work is that a higher DCQ score was associated with lower QoL, consistent with previous studies of ACEs and well-being [56]. However, in our mediation analysis, the direct negative association of DCQ score with QoL was rather modest based on a nominal evaluation: a one-unit increase in the 5-point DCQ scale accounted for a 0.04 decrease on the 10-point QoL scale. The negative effect association between DCQ score and QoL grew substantially when mental distress and loneliness, both possible residues of childhood adversities, were examined as mediating mechanisms: a one-unit increase in the DCQ led to a total 0.84 reduction in the QoL score when these indirect effects were added to the model, representing a quite strong negative influence on a 10-point scale. Thus, our model demonstrated that mental health and feelings of social isolation are conduits for childhood adversities to exert their influence on overall measures of health in adulthood, such as QoL.

We have not identified previous QoL studies examining mediation processes in a latent SEM framework, but our finding resembles reports from previous studies of ACEs and QoL. In a U.S. community-based study, the influence of ACE score on health-related QoL weakened when potential sequelae of ACEs (stress and sleep disturbances) were added to the model [57]. Indeed, the direct influence of ACEs on health-related QoL became non-significant when these mediators were added, which indicates total mediation [57]. Together, such findings support the notion that studies should not focus on the mere presence of ACEs but examine possible pathways that connect childhood adversities to health outcomes [58]. The question to address is whether childhood adversities resulting in health impairments depend on the proximal mechanisms at work. From a treatment perspective, the good news is that clinicians have effective interventions directed at the potential sequelae of ACEs, including post-traumatic stress disorder, depression, and substance use disorders. When adults with ACEs need help, they can receive support that includes existing effective remedies targeting these conditions [24].

\section{Methodological considerations}

Among the strengths of this study is its large sample size drawn from a general population. The novelty of the current study is the development of a short instrument that includes reflective items. The methodology typically used in this field relies on a detailed mapping of specific experiences, which may be perceived as intrusive and stigmatizing and increase non-response. A review of the validity of retrospective reports of ACEs among adults has shown that such reports may include a substantial number of false negatives [59]. The DCQ used in our study can potentially reduce this under-reporting. However, retrospective bias, such as the possibility that resilient adults have made cognitive adjustments of their evaluations of childhood, cannot be avoided even with use of reflective indicators. Another limitation is that the general nature of our measure could limit the 
possibility of examining specific ACEs, such as whether differing types of maltreatment are differentially associated with adult health outcomes, e.g., depression [60].

\section{Conclusions}

The DCQ offers an empirically supported method of assessing ACEs. It is well suited to clinical settings because it is brief and likely to be amenable to people seeking mental health treatment. Its brevity and psychometric strengths make it useful for research purposes ranging from large, epidemiological studies to intervention trials. Use of the DCQ in treatment and research settings should benefit people who continue to struggle with the aftermath of ACEs.

Acknowledgements We acknowledge the work of the HUNT Databank (HUNT Research Centre, Norwegian University of Science and Technology), who developed the items included in the DCQ.

Author contributions JKV and SHH designed the study. JKV performed the analyses. All authors participated in the interpretation of the findings and drafting of the manuscript and approved the final version.

Funding Open Access funding provided by University of Agder. There was no external funding for this study. CT was supported by the U.S. Department of Veterans Affairs (HSR\&D RCS 00-001).

Data availability The controller for this public health survey (NIPH) will deposit the data in a publicly available data repository: https://helse data.no/en/. For more information, contact the first author.

\section{Compliance with ethical standards}

Conflict of interest The authors declare that they have no conflict of interest.

Consent to participate The online survey began with an introductory page that included information about the study's purpose and a consent form, which respondents had to click on and agree to before they were directed to the questionnaire.

Ethical approval The controller for the county public health survey is the Norwegian Institute of Public Health (NIPH). The survey was approved by the Norwegian Data Inspectorate and followed the regulations in the Personal Health Data Filing System Act. A Data Protection Impact Assessment was completed before data collection started, and the Regional Ethics Committee approved the overall project. Before the current study received any data, the NIPH removed all personal identification variables. Data are stored and processed in compliance with applicable personal data protection regulation. The Regional Committees for Medical and Health Research Ethics (REC) in Norway (REC South East-C) also approved the current study (REC No. 162353/2020).

Open Access This article is licensed under a Creative Commons Attribution 4.0 International License, which permits use, sharing, adaptation, distribution and reproduction in any medium or format, as long as you give appropriate credit to the original author(s) and the source, provide a link to the Creative Commons licence, and indicate if changes were made. The images or other third party material in this article are included in the article's Creative Commons licence, unless indicated otherwise in a credit line to the material. If material is not included in the article's Creative Commons licence and your intended use is not permitted by statutory regulation or exceeds the permitted use, you will need to obtain permission directly from the copyright holder. To view a copy of this licence, visit http://creativecommons.org/licenses/by/4.0/.

\section{References}

1. Bellis, M. A., Hughes, K., Ford, K., Ramos Rodriguez, G., Sethi, D., \& Passmore, J. (2019). Life course health consequences and associated annual costs of adverse childhood experiences across Europe and North America: A systematic review and meta-analysis. Lancet Public Health, 4(10), e517e528. https://doi.org/10.1016/S2468-2667(19)30145-8.

2. WHO. (2014). Investing in children: The European child maltreatment prevention action plan 2015-2020. Copenhagen: World Health Organization.

3. Merrick, M. T., Ports, K. A., Ford, D. C., Afifi, T. O., Gershoff, E. T., \& Grogan-Kaylor, A. (2017). Unpacking the impact of adverse childhood experiences on adult mental health. Child Abuse and Neglect, 69, 10-19. https://doi.org/10.1016/j.chiab u.2017.03.016.

4. Ferrara, P., Guadagno, C., Sbordone, A., Amato, M., Spina, G., Perrone, G., et al. (2016). Child abuse and neglect and its psycho-physical and social consequences: A review of the literature. Current Pediatric Reviews, 12(4), 301-310. https://doi. org/10.2174/1573396312666160914193357.

5. Hughes, K., Bellis, M. A., Hardcastle, K. A., Sethi, D., Butchart, A., Mikton, C., et al. (2017). The effect of multiple adverse childhood experiences on health: A systematic review and metaanalysis. Lancet Public Health, 2(8), e356-e366. https://doi. org/10.1016/S2468-2667(17)30118-4.

6. Lu, W., Mueser, K. T., Rosenberg, S. D., \& Jankowski, M. K. (2008). Correlates of adverse childhood experiences among adults with severe mood disorders. Psychiatric Services, 59(9), 10181026. https://doi.org/10.1176/ps.2008.59.9.1018.

7. World Health Organization. (2013). Global action plan for the prevention and control of noncommunicable diseases 2013-2020. Geneva: World Health Organization.

8. Merz, E. M., \& Consedine, N. S. (2009). The association of family support and wellbeing in later life depends on adult attachment style. Attachment \& Human Development, 11(2), 203-221. https ://doi.org/10.1080/14616730802625185.

9. Edwards, V. J., Anda, R. F., Felitti, V. J., \& Dube, S. R. (2004). Adverse childhood experiences and health-related quality of life as an adult. In K. A. Kendall-Tackett (Ed.), Application and practice in health psychology. Health consequences of abuse in the family: A clinical guide for evidence-based practice (pp. 81-94). Washington, DC: American Psychological Association.

10. Holt-Lunstad, J. (2018). Why social relationships are important for physical health: A systems approach to understanding and modifying risk and protection. Annual Review of Psychology, 69, 437-458. https://doi.org/10.1146/annurev-psych-122216-011902.

11. Shevlin, M., McElroy, E., \& Murphy, J. (2015). Loneliness mediates the relationship between childhood trauma and adult psychopathology: Evidence from the adult psychiatric morbidity survey. Social Psychiatry and Psychiatric Epidemiology, 50(4), 591-601. https://doi.org/10.1007/s00127-014-0951-8.

12. Merz, E. M., \& Jak, S. (2013). The long reach of childhood. Childhood experiences influence close relationships and loneliness 
across life. Advances in Life Course Research, 18(3), 212-222. https://doi.org/10.1016/j.alcr.2013.05.002.

13. Birmingham, W. C., \& Holt-Lunstad, J. (2018). Social aggravation: Understanding the complex role of social relationships on stress and health-relevant physiology. International Journal of Psychophysiology, 131, 13-23. https://doi.org/10.1016/j.ijpsy cho.2018.03.023.

14. Hakulinen, C., Pulkki-Raback, L., Jokela, M., Ferrie, J. E., Aalto, A.-M., Virtanen, M., et al. (2016). Structural and functional aspects of social support as predictors of mental and physical health trajectories: Whitehall II cohort study. Journal of Epidemiology and Community Health, 70(7), 710-715. https://doi. org/10.1136/jech-2015-206165.

15. Holt-Lunstad, J., Smith, T. B., Baker, M., Harris, T., \& Stephenson, D. (2015). Loneliness and social isolation as risk factors for mortality: A meta-analytic review. Perspectives on Psychological Science, 10(2), 227-237. https://doi.org/10.1177/1745691614 568352.

16. Hawthorne, G. (2008). Perceived social isolation in a community sample: Its prevalence and correlates with aspects of peoples' lives. Social Psychiatry and Psychiatric Epidemiology, 43(2), 140-150. https://doi.org/10.1007/s00127-007-0279-8.

17. Burgermeister, D. (2007). Childhood adversity: A review of measurement instruments. Journal of Nursing Measurement, 15(3), 163-176. https://doi.org/10.1891/106137407783095766.

18. Larkin, H., Shields, J. J., \& Anda, R. F. (2012). The health and social consequences of adverse childhood experiences (ACE) across the lifespan: An introduction to prevention and intervention in the community. Journal of Prevention \& Intervention Community, 40(4), 263-270. https://doi.org/10.1080/10852 352.2012.707439.

19. Chapman, D. P., Whitfield, C. L., Felitti, V. J., Dube, S. R., Edwards, V. J., \& Anda, R. F. (2004). Adverse childhood experiences and the risk of depressive disorders in adulthood. Journal of Affective Disorders, 82(2), 217-225. https://doi.org/10.1016/j. jad.2003.12.013.

20. Bellis, M. A., Hughes, K., Leckenby, N., Jones, L., Baban, A., Kachaeva, M., et al. (2014). Adverse childhood experiences and associations with health-harming behaviours in young adults: Surveys in eight eastern European countries. Bulletin of the World Health Organization, 92(9), 641-655. https://doi.org/10.2471/ BLT.13.129247.

21. Dong, M., Anda, R. F., Felitti, V. J., Dube, S. R., Williamson, D. F., Thompson, T. J., et al. (2004). The interrelatedness of multiple forms of childhood abuse, neglect, and household dysfunction. Child Abuse and Neglect, 28(7), 771-784. https://doi. org/10.1016/j.chiabu.2004.01.008.

22. Burt, K. B., \& Paysnick, A. A. (2012). Resilience in the transition to adulthood. Development and Psychopathology, 24(2), 493-505. https://doi.org/10.1017/S0954579412000119.

23. Leung, D. Y. L., Chan, A. C. Y., \& Ho, G. W. K. (2020). Resilience of emerging adults after adverse childhood experiences: A qualitative systematic review. Trauma Violence Abuse. https://doi. org/10.1177/1524838020933865.

24. Finkelhor, D. (2018). Screening for adverse childhood experiences (ACEs): Cautions and suggestions. Child Abuse and Neglect, 85, 174-179. https://doi.org/10.1016/j.chiabu.2017.07.016.

25. Reeves, E. (2015). A synthesis of the literature on traumainformed care. Issues in Mental Health Nursing, 36(9), 698-709. https://doi.org/10.3109/01612840.2015.1025319.

26. Felitti, V. J., Anda, R. F., Nordenberg, D., Williamson, D. F., Spitz, A. M., Edwards, V., et al. (1998). Relationship of childhood abuse and household dysfunction to many of the leading causes of death in adults. The Adverse Childhood Experiences (ACE) Study. American Journal of Preventive Medicine, 14(4), 245-258. https://doi.org/10.1016/s0749-3797(98)00017-8.
27. Tomasdottir, M. O., Sigurdsson, J. A., Petursson, H., Kirkengen, A. L., Krokstad, S., McEwen, B., et al. (2015). Self reported childhood difficulties, adult multimorbidity and allostatic load. A crosssectional analysis of the Norwegian HUNT study. PLoS ONE, 10(6), e0130591. https://doi.org/10.1371/journal.pone.0130591.

28. Derogatis, L. R., Lipman, R. S., Rickels, K., Uhlenhuth, E. H., \& Covi, L. (1974). The Hopkins Symptom Checklist (HSCL): A self-report symptom inventory. Behavioral Science, 19(1), 1-15. https://doi.org/10.1002/bs.3830190102.

29. Strand, B. H., Dalgard, O. S., Tambs, K., \& Rognerud, M. (2003). Measuring the mental health status of the Norwegian population: A comparison of the instruments SCL-25, SCL-10, SCL-5 and MHI-5 (SF-36). Nordic Journal of Psychiatry, 57(2), 113-118. https://doi.org/10.1080/08039480310000932.

30. Hughes, M. E., Waite, L. J., Hawkley, L. C., \& Cacioppo, J. T. (2004). A short scale for measuring loneliness in large surveys: Results from two population-based studies. Research on Aging, 26(6), 655-672. https://doi.org/10.1177/0164027504268574.

31. Hodgins, D. C., Maticka-Tyndale, E., El-Guebaly, N., \& West, M. (1993). The cast-6: Development of a short-form of the children of alcoholics screening test. Addictive Behaviors, 18(3), 337-345. https://doi.org/10.1016/0306-4603(93)90035-8.

32. Jones, J. W. (1983). The children of alcoholics screening test: A validity study. Bulletin of the Society of Psychologists in Addictive Behaviors, 2(3), 155-163.

33. Hodgins, D. C., \& Shimp, L. (1995). Identifying adult children of alcoholics: Methodological review and a comparison of the CAST-6 with other methods. Addiction, 90(2), 255-267. https:// doi.org/10.1046/j.1360-0443.1995.90225511.x.

34. Elgán, T., Berman, A., Jayaram-Lindström, N., Hammarberg, A., Jalling, C., \& Kallmen, H. (2020). Psychometric properties of the short version of the children of alcoholics screening test (CAST-6) among Swedish adolescents. Nordic Journal of Psychiatry. https ://doi.org/10.1080/08039488.2020.1812000.

35. Kelly, J. F., Saitz, R., \& Wakeman, S. (2016). Language, substance use disorders, and policy: The need to reach consensus on an "addiction-ary." Alcoholism Treatment Quarterly, 34(1), 116-123. https://doi.org/10.1080/07347324.2016.1113103.

36. Nes, R. B., Hansen, T., \& Barstad, A. (2018). Quality of Life. Recommendations for a better way of measuring it. [Livskvalitet. Anbefaling for et bedre målesystem]. Oslo: The Norwegian Directorate of Health.

37. Phillips, D. (2006). Quality of life: Concept, policy and practice. London: Routledge.

38. Ryan, R. M., \& Deci, E. L. (2001). On happiness and human potentials: A review of research on hedonic and eudaimonic wellbeing. Annual Review of Psychology, 52, 141-166. https://doi. org/10.1146/annurev.psych.52.1.141.

39. Brown, T. A. (2006). Confirmatory factor analysis for applied research (Methodology in the social sciences). New York: Guilford Press.

40. Muthén, L. K., \& Muthén, B. O. (2017). Mplus user's guide (8th ed.). Los Angeles, CA: Muthén \& Muthén.

41. Browne, M. W., \& Cudeck, R. (1993). Alternative ways of assessing model fit. In K. A. Bollen \& J. S. Long (Eds.), Testing structural equation models (Vol. 154, pp. 136-162). Cnewbury Park: Sage.

42. Little, T. D. (2013). Longitudinal structural equation modeling (Methodology in the social sciences). New York: Guilford Press.

43. Byrne, B. M., Shavelson, R. J., \& Muthen, B. (1989). Testing for the equivalence of factor covariance and mean structures: The issue of partial measurement invariance. Psychological Bulletin, 105(3), 456-466. https://doi.org/10.1037/0033-2909.105.3.456.

44. Peterson, R. A., \& Kim, Y. (2013). On the relationship between coefficient alpha and composite reliability. Journal of Applied 
Psychology, 98(1), 194-198. https://doi.org/10.1037/a003076723 127213.

45. Hayes, A. F., \& Coutts, J. J. (2020). Use omega rather than Cronbach's alpha for estimating reliability. But... Communication Methods and Measures, 14(1), 1-24. https://doi. org/10.1080/19312458.2020.1718629.

46. Steinmetz, H., Schmidt, P., Tina-Booh, A., Wieczorek, S., \& Schwartz, S. (2009). Testing measurement invariance using multigroup CFA: Differences between educational groups in human values measurement. Quality \& Quantity, 43(4), 599-616. https ://doi.org/10.1007/s11135-007-9143-x.

47. Steenkamp, J. E. M., \& Baumgartner, H. (1998). Assessing measurement invariance in cross-national consumer research. Journal of Consumer Research, 25(1), 78-107. https://doi. org/10.1086/209528.

48. Putnick, D. L., \& Bornstein, M. H. (2016). Measurement invariance conventions and reporting: The state of the art and future directions for psychological research. Developmental Review, 41, 71-90. https://doi.org/10.1016/j.dr.2016.06.004.

49. Cheung, G. W., \& Rensvold, R. B. (2002). Evaluating goodnessof-fit indexes for testing measurement invariance. Structural Equation Modeling, 9(2), 233-255. https://doi.org/10.1207/S1532 8007SEM0902_5.

50. Chen, F. F., Sousa, K. H., \& West, S. G. (2005). Testing measurement invariance of second-order factor models. Structural Equation Modeling, 12(3), 471-492. https://doi.org/10.1207/s1532 8007sem1203_7.

51. Brown, T. A. (2015). Confirmatory factor analysis for applied research (Methodology in the social sciences) (2nd ed.). New York: Guilford Press.

52. Hancock, G. R. (2001). Effect size, power, and sample size determination for structured means modeling and MIMIC approaches to between-groups hypothesis testing of means on a single latent construct. Psychometrika, 66(3), 373-388. https://doi. org/10.1007/BF02294440.

53. Chanlongbutra, A., Singh, G. K., \& Mueller, C. D. (2018). Adverse childhood experiences, health-related quality of life, and chronic disease risks in rural areas of the United States. Journal of Environmental and Public Health, 2018, 7151297. https://doi. org/10.1155/2018/7151297.

54. Starecheski, L. (2015). Take The ACE quiz-and learn what it does and doesn't mean. https://www.npr.org/sections/health-shots /2015/03/02/387007941/take-the-ace-quiz-and-learn-what-itdoes-and-doesnt-mean? Accessed 14 Sep 2020.

55. Stevens, J. E. Got Your ACE Score? https://acestoohigh.com/gotyour-ace-score/. Accessed 15 Sep 2020.

56. Mosley-Johnson, E., Garacci, E., Wagner, N., Mendez, C., Williams, J. S., \& Egede, L. E. (2019). Assessing the relationship between adverse childhood experiences and life satisfaction, psychological well-being, and social well-being: United States Longitudinal Cohort 1995-2014. Quality of Life Research, 28(4), 907-914. https://doi.org/10.1007/s11136-018-2054-6.

57. Salinas-Miranda, A. A., Salemi, J. L., King, L. M., Baldwin, J. A., Berry, E. L., Austin, D. A., et al. (2015). Adverse childhood experiences and health-related quality of life in adulthood: Revelations from a community needs assessment. Health Qual Life Outcomes, 13, 123. https://doi.org/10.1186/s12955-015-0323-4.

58. Kendall-Tackett, K. (2002). The health effects of childhood abuse: Four pathways by which abuse can influence health. Child Abuse and Neglect, 26(6-7), 715-729. https://doi.org/10.1016/s0145 -2134(02)00343-5.

59. Hardt, J., \& Rutter, M. (2004). Validity of adult retrospective reports of adverse childhood experiences: Review of the evidence. Journal of Child Psychology and Psychiatry, 45(2), 260-273. https://doi.org/10.1111/j.1469-7610.2004.00218.x.

60. Humphreys, K. L., LeMoult, J., Wear, J. G., Piersiak, H. A., Lee, A., \& Gotlib, I. H. (2020). Child maltreatment and depression: A meta-analysis of studies using the Childhood Trauma Questionnaire. Child Abuse and Neglect, 102, 104361. https://doi. org/10.1016/j.chiabu.2020.104361.

Publisher's Note Springer Nature remains neutral with regard to jurisdictional claims in published maps and institutional affiliations. 